\title{
Chemical and Electrochemical Properties of Bamboo Acti- vated Garhon Activate using Potassium Hydroxide Assisted by Microwave-Ultrasonic Irradiation
}

\author{
Norakmalah Mohd Zawawi ${ }^{1}$ \\ Fazlena Hamzah ${ }^{1^{*}}$ \\ Harumi Veny ${ }^{1}$ \\ Miradatul Najwa Mohd Rodhi ${ }^{1}$ \\ Mahanim Sarif ${ }^{2}$ \\ ${ }^{1}$ Biocatalysis and Biobased Material Technology Research Laboratory, School of Chemical Engi- \\ neering, College of Engineering, Universiti Teknologi MARA, Selangor, Malaysia \\ ${ }^{2}$ Forest Product Division, Forest Research Institute Malaysia, 52109 Kepong, Selangor, Malaysia \\ *e-mail: fazlena@uitm.edu.my
}

Submitted 10 March 2021

Revised 18 October 2021

Accepted 23 November 2021

\begin{abstract}
This paper presents the utilization of bamboo residue from the chopstick industry as modified carbon (AC) for supercapacitor application. Bamboo activated carbon (BAC) was activated using Potassium hydroxide $(\mathrm{KOH})$ and assisted with microwave ultrasonic (Mw-U) irradiation to enhance the properties of bamboo activated carbon (BAC). Different microwave (Mw) power intensities of $100 \mathrm{~W}, 300 \mathrm{~W}$, and $500 \mathrm{~W}$ at 30 minutes of retention time have been applied on activation and the carbonization process was conducted at temperature $800^{\circ} \mathrm{C}$. The $\mathrm{BAC}$ was analyzed for the morphology using a scanning electron microscope and proximate and ultimate analysis. Then BAC with the higher surface area was subjected to the electrochemical analysis to determine the electrochemical properties. The study indicated $\mathrm{Mw}-\mathrm{U}$ irradiation improved the morphology of the BAC, eliminated the impurity of the sample, and gave higher carbon content of BAC. The findings show that lower $\mathrm{Mw}-\mathrm{U}$ irradiation power provided a higher surface area of BAC. The surface area of $646.87 \mathrm{~m}^{2} / \mathrm{g}$ and total pore volume of $2.8 \times 10^{-1} \mathrm{~cm}^{3} / \mathrm{g}$ was obtained with a power intensity of $\mathrm{Mw}-\mathrm{U}$ activation at $100 \mathrm{~W}$. While, electrochemical properties, the specific capacitance $\left(C_{s}\right)$ of BAC was $77 \mathrm{Fg}^{-1}$ at $25 \mathrm{mVs}^{-1}$ in $1 \mathrm{~mol} / \mathrm{L} \mathrm{KOH}$ of electrolyte for cyclic voltammetry (CV) which indicates the ability of the prepared BAC to be used as an electrode in supercapacitor application. This study determined that $\mathrm{Mw}-\mathrm{U}$ irradiation can improve the properties of the bamboo during chemical activation and formed BAC that consists of supercapacitor properties.
\end{abstract}

Keywords: Activated carbon, Bamboo, Electrochemical, Microwave, Ultrasonic

\section{INTRODUCTION}

Activated carbon (AC) derived from a carbon precursor gave an amorphous structure to exhibit an extended interparticle surface area and a high degree of porosity. Besides, having a large internal pore structure is common terminology for a group of adsorbing substances. Activated carbon is also known as activated charcoal produced from carbonaceous material with a unique characteristic leading to high adsorptive capacity, porosity, greater strength and carbon content (Cukierman, 2013). It is a non-graphitic carbon and microcrystalline structure that develops an internal porosity. The porosity yield provides a higher surface area to adsorb gases and vapors from gases and assimilate dispersed or dissolved substances from the liquid. In the 

Potassium Hydroxide Assisted By Microwave-Ultrasonic Irradiation

adsorption process, the impurities are trapped within the porous structure of $A C$ by a strong physical bond (Itodo et al., 2012). The tenable porosity and surface chemistry of AC greatly impact AC applications. Adsorbent $A C$ has been widely used in industrial applications such as purification of gases, liquid phase recovery, catalyst support, water treatment, electronic and solution purification (Çeçen, 2014). In 2016, the demand for activated carbon increased up to 1.9 million metric tons, with an increment of more than ten per cent per year. Based on market analysis by Mordor Intelligence, in 2020, the activated carbon market was valued at around 1,666 kiloton, and it was projected that the Compound Annual Growth Rate (CAGR) for activated carbon from 2021 - 2026 is more than $3 \%$ due to the current industrial demand especially in wastewater. The application of AC keeps increasing yearly due to the societal demand and the unique characteristics of $A C$.

Commercial activated carbon is processed starting with non-renewable precursors such as pitch, coke and coal-based feedstock with high carbon and low inorganic content. However, this precursor has contributed to high processing pricing. Agricultural and agro-based by-products or waste have been recently attempted for usage to reduce the cost of the AC. Biomass precursors also have been explored as a cheap source in the formation of powder activated carbon. It is due to the chemical, physical and electrochemical properties of the derived AC. The common biomass used in AC production is oil-palm stone, pistachio nutshells, candlenut shell, teak sawdust, fir wood, rice bran, coffee endocarp, rubberwood sawdust (Kalyani and Anitha, 2013) and mangosteen shell carbon (Prasetyo et al., 2018). Another potential biomass precursor which is available plentifully in Malaysia is bamboo. Bamboo is a cellulose and lignose biomass that grows faster and can be harvested in high quantities in Malaysia (Jiang et al., 2012). Bamboo is a plant that has low-density materials and low material cost yet yields high mechanical strength, stiffness and growth rate. As reported by Peng et al., 2018, bamboo has moderate-high carbon content $(48.64 \%)$ and a low amount of nitrogen $(0.14 \%)$, sulfur $(0.11 \%)$ and hydrogen (6.75\%). Thus, bamboo is selected as the AC precursor in the present study with these criteria.

AC has been widely used as electrode material in the electrochemical industry. Some of the AC derived from corn grains, waste coffee beans, seaweed biopolymers, fir wood, sugarcane bagasse, and banana fibers have been extensively explored in supercapacitor application due to the microstructure absorptive capacity of the derived AC. AC as an electrode for supercapacitor application must be possed the criteria such as stable material, high energy storage, and reversible electrical energy storage capacity, which can be achieved by using AC with a large surface area, high conductivity, and long-term cycle. By considering these factors, bamboo AC can be further explored as an electrode in supercapacitor due to its porous microstructure and high absorptive capacity. These properties make it suitable for adsorption and desorption of electrolyte ions without chemical reactions, and with the high conductive properties of bamboo $A C$, the rapid charging process can occur (Taer et al., 2011). The electrochemical performance such as electrical conductivity, pore-size distribution, carbon surface area, and the presence of electrochemically active surface functional groups that affect the double layer capacitance of AC electrodes depends on the activation process of AC. To produce high specific capacitance for supercapacitor within the range $70 \mathrm{Fg}^{-1}$ to 
$200 \mathrm{Fg}^{-1}$ or above, good performance of $\mathrm{AC}$ properties based on the high surface area which is exceeding than $500 \mathrm{~m}^{2} / \mathrm{g}$ and development of pores structures under mesopores $(2-50 \mathrm{~nm})$ or micropores $(<2 \mathrm{~nm})$ must be prioritized. AC interface, which appeared as a double layer, influenced the effect of the capacitor due to the specific surface area and pore size in capacitance value.

The activation process plays an essential role in producing provided $A C$ to obtain a higher specific surface area of AC. Chemical activation has been preferred in bulk production of AC because of the simple process, shorter activation time, produce higher yield, use a lower temperature and provide better development of the porous structure. As reported by Yang et al. (2014) and Zhang et al. (2018) in their study on $\mathrm{KOH}$ activation of bamboo as a precursor in $A C$, the higher surface area of $A C$ more than $2000 \mathrm{~m}^{2} \mathrm{~g}^{-1}$ has been synthesized, which has contributed to a large capacitance $\left(>290 \mathrm{Fg}^{-1}\right)$ material. The activation process implemented in their study involved chemical soaking only.

Recently integration of the physical and chemical method has been introduced as a viable alternative in the production of $A C$ such as microwave (MW) - chemical activation or ultrasonic - chemical activation due to the fast, selective, uniform and volumetric heating process, instant and accurate control, and non-direct contact between the heating source and heated materials (Salanne et al., 2016; Taer et al., 2011). As reported by Wang et al. (2012), AC can be further treated using various activation processes such as chemical activation and microwave irradiation. Ultrasonic activation is alternative for enhancing the surface properties. Fu et al. (2020) indicated that a combination of physical-chemical treatment such as ultrasonic with hydrochloric acid in AC activation gave the optimum approach in getting higher total pore size, specific surface area, micropore volume, and low average pore size. However, integration between ultrasonic and microwave heating in the activation process of $A C$ has not been explored yet. It is believed that power characteristics and cavitation will significantly change the physical and chemical properties of the AC. Hence, this study was conducted to elucidate the chemical and electrochemical characteristics of the prepared Microwave Ultrasonic Activation (Mw$\mathrm{U})$ of Bamboo Activated Carbon (BAC).

\section{MATERIALS AND METHODS Materials}

Semantan bamboo or Gigantochloa scortechinii provided by Forest Research Institute Malaysia (FRIM) was washed and dried in the oven at $110^{\circ} \mathrm{C}$ for $6 \mathrm{hr}$. Then, the bamboo sample was ground and sieved into less than $710 \mu \mathrm{m}$ particles size. The Semantan bamboo samples were kept in sealed plastic containers before further processing.

\section{Bamboo Activated Carbon (BAC) Prepara- tion}

Activated carbon was prepared using Semantan bamboo precursor and chemically activated with potassium hydroxide $(\mathrm{KOH})$ (R\&M Chemical, Inc). In the activation process, dried Semantan bamboo (50g) was placed into the crucible, and the $\mathrm{KOH}$ was added into the bamboo sample, with the volume ratio of $\mathrm{KOH}$ was set at 1:4. The experimental setup is tabulated in Table 1. The sample was stirred to ensure complete mixing and then underwent ultrasonic activation. The ultrasonic was set at $45^{\circ} \mathrm{C}$ in $80 \mathrm{~Hz}$ of ultrasonic frequency. Then, the soaked bamboo was irradiated with microwave activation in different microwave power of $100 \mathrm{~W}, 300 \mathrm{~W}$ and $500 \mathrm{~W}$ for $30 \mathrm{~min}$. Activated samples 

Potassium Hydroxide Assisted By Microwave-Ultrasonic Irradiation

were cooled and washed with distilled water until $\mathrm{pH}$ 6-7. Then, the sample was dried in the oven at $110^{\circ} \mathrm{C}$ for $24 \mathrm{~h}$ (Mahanim et al., 2011). Next, the samples were carbonized in the VT Furnace (Carbolite, Keison) for two $h$ at $800^{\circ} \mathrm{C}$. After the carbonization process, the temperature of BAC was reduced to the ambient temperature for further analysis. The prepared BAC was analyzed for the chemical functioning group using FTIR - Fourier transforms infrared spectroscopy, morphology analysis using FESEM - Field Emission Scanning Electron Microscope and constituent composition using ultimate and proximate analysis.

Table 1. Experimental Set Up BAC

\begin{tabular}{cccc}
\hline Sample & $\begin{array}{c}\text { Ultrasonic } \\
\text { Soaking } \\
\text { (time, min) }\end{array}$ & $\begin{array}{c}\text { Microwave } \\
\text { Power Inten- } \\
\text { sity (watt) }\end{array}$ & $\begin{array}{c}\text { Carboniza- } \\
\text { tion tem- } \\
\text { pera- } \\
\text { ture, }{ }^{\circ} \text { C }\end{array}$ \\
\hline BAC A & 60 & 100 & 800 \\
BAC B & 60 & 300 & 800 \\
BAC C & 60 & 500 & 800 \\
\hline
\end{tabular}

\section{Electrochemical Analysis}

The electrode was prepared by $70 \mathrm{wt}$.\% of dried BAC, 15 wt.\% of conducting carbon (Super $\mathrm{P}$ ), and $15 \mathrm{wt}$ \% of polyvinylidene fluoride were mixed with $\mathrm{N}$-methyl pyrrolidinone, stirred overnight to form a slurry. Then, the slurry was coated onto a substrate (nickel foam). The coated electrode was annealed at $60^{\circ} \mathrm{C}$ in an oven for $24 \mathrm{~h}$. Hydraulic press at $5 \mathrm{MPa}$ was used to press the annealed sample. Cyclic voltammetry (CV), galvanostatic charge and discharge (CDC), and electrochemical impedance spectroscopy (EIS) analysis were used to determine the electrochemical properties of the developed electrode. The potentiostat galvanostat (Autolab PGSTAT 30, Eco Chemie BV) was configurated at $-1.0-0.0 \mathrm{~V}$, different scan rates and in three electrodes setting to determine the CV of the electrode. For stability of the electrode, galvanostatic CDC was determined by cycling the potential from -1.0 to $0.0 \mathrm{~V}$ at the current densities range of $10-0.5 \mathrm{Ag}^{-1}$. The performance of the chemical and physically AC electrodes was tested with $1 \mathrm{~mol} / \mathrm{L} \mathrm{KOH}$ electrolyte. Electrochemical Impedance Spectroscopy (EIS) in the frequency range of $10 \mathrm{kHz}$ to $10 \mathrm{MHz}$ was used to determine the alternating current (a.c) response of the electrical double-layer capacitor (EDLC) for the produced electrode. The analysis was conducted using the Autolab potentiostat with platinum (Pt) as the counter electrode and $\mathrm{Ag} / \mathrm{AgCl}$ as the reference electrode.

\section{Elemental Analysis}

The Elemental Analyzer (EA) (Thermo, Flash EA-1112, (United States)) with helium gas as a carrier was used to determine the percentages of Carbon (C), Nitrogen $(\mathrm{N})$ and Sulphur (S) in the BAC. The BAC samples were loaded in the sample loading chamber, and the sample was held until the dose of oxygen was released. The helium carrier carried out the analysis, and the results were displayed as weight per cent of $\mathrm{C}, \mathrm{H}, \mathrm{N}$ and $\mathrm{S}$ elements.

\section{Functioning Group Analysis}

The FTIR (Spectrum One, Perkin Elmer, United States) analysis was used to determine the chemical bonds in BAC molecules by functioning group spectrum. The sample was placed into the diamond mold and operated using FTIR software. FTIR spectra of functional group peaks were recorded between $4000 \mathrm{~cm}^{-1}$ and $500 \mathrm{~cm}^{-1}$ using AVATAR 360 Spectrophotometer. 


\section{Surface Morphology Analysis}

The morphology of the samples, the composition, distribution and phase structure were analyzed using Field Emission Scanning Electron Microscope (FESEM) (Supra 40VP, Zeiss, Germany). In FESEM analyses, BAC samples were coated with gold to prevent the increase of electrostatic charge at the surface of the samples. The magnificent FESEM analyses were undergone $500 \mathrm{x}$ and $1 \mathrm{~K}$ in getting a clear morphology image of BAC.

\section{Pore size and Surface area analysis}

BAC samples were characterized under the BET analyses software and instrument to determine the surface area and pore size of bamboo AC The BET analyzer was set at the ambient temperature of $22^{\circ} \mathrm{C}$ using Quantachrome (Autosorb-1) from the USA. The gas adsorption, $\mathrm{N}_{2}$ was measured in vacuum for $12 \mathrm{~h}$ with automatic degassed. The BET surface area was measured employing a standard BET equation applied in the relative pressure of $P / P_{o}=0$. The equilibration intervals for BET analyses was $5 \mathrm{~s}$ with a BAC weight mass of $0.05 \mathrm{~g}$, and the analyses of
BET was completed within $10 \mathrm{~h}$.

\section{RESULTS AND DISCUSSION}

\section{Chemical properties and Morphology of the Prepared BAC}

Proximate and ultimate analyses of BAC were conducted. The chemical constituent for each of the BAC is summarized in Table 2. The result indicates that BAC A provided a high carbon content with a value of $83.42 \%$. In contrast, BAC B and C gave $77.50 \%$ and $63.52 \%$ carbon content. On the other hand, raw bamboo consists of $47 \%$ carbon. BAC B gives the lowest value for volatile matter and ash content, $6.7 \%$ and $27.5 \%$, respectively. Increment of the carbon content and decrement of other constituents in this process were indicators of the process's effectiveness. According to Rodriquez and Mazzoco (2010), solid yield in the carbonization stage will be reduced if the carbon sample consists of high volatile matter. On the other hand, low inorganic content is required to produce low ash and high fixed carbon content.

Table 2. Proximate and Ultimate Analysis of BAC

\begin{tabular}{lccccccccc}
\hline Sample & \multicolumn{2}{c}{ Proximate analyses (dry basis) } & \multicolumn{7}{c}{ Ultimate analyses } \\
& $\begin{array}{c}\text { Moisture } \\
\text { content }\end{array}$ & $\begin{array}{c}\text { Volatile } \\
\text { matter }\end{array}$ & $\begin{array}{c}\text { Ash } \\
\text { content }\end{array}$ & $\begin{array}{c}\text { Fixed } \\
\text { carbon }\end{array}$ & $\mathbf{C}$ & $\mathbf{N}$ & $\mathbf{H}$ & $\mathbf{S}$ & $\mathbf{0}$ \\
\hline Raw & 7.08 & 43.76 & 35.38 & 13.76 & 47.26 & 0.20 & 0.31 & 0 & 52.07 \\
Bamboo & & & & & & & & & \\
BAC A & 0.4 & 7.2 & 46.8 & 45.6 & 83.42 & 0 & 3.05 & 0 & 13.53 \\
BAC B & 4.0 & 6.7 & 27.5 & 61.8 & 77.50 & 0 & 3.65 & 0 & 18.85 \\
BAC C & 12.4 & 6.9 & 26.9 & 53.8 & 63.52 & 0 & 1.12 & 0 & 35.36 \\
\hline
\end{tabular}



Potassium Hydroxide Assisted By Microwave-Ultrasonic Irradiation

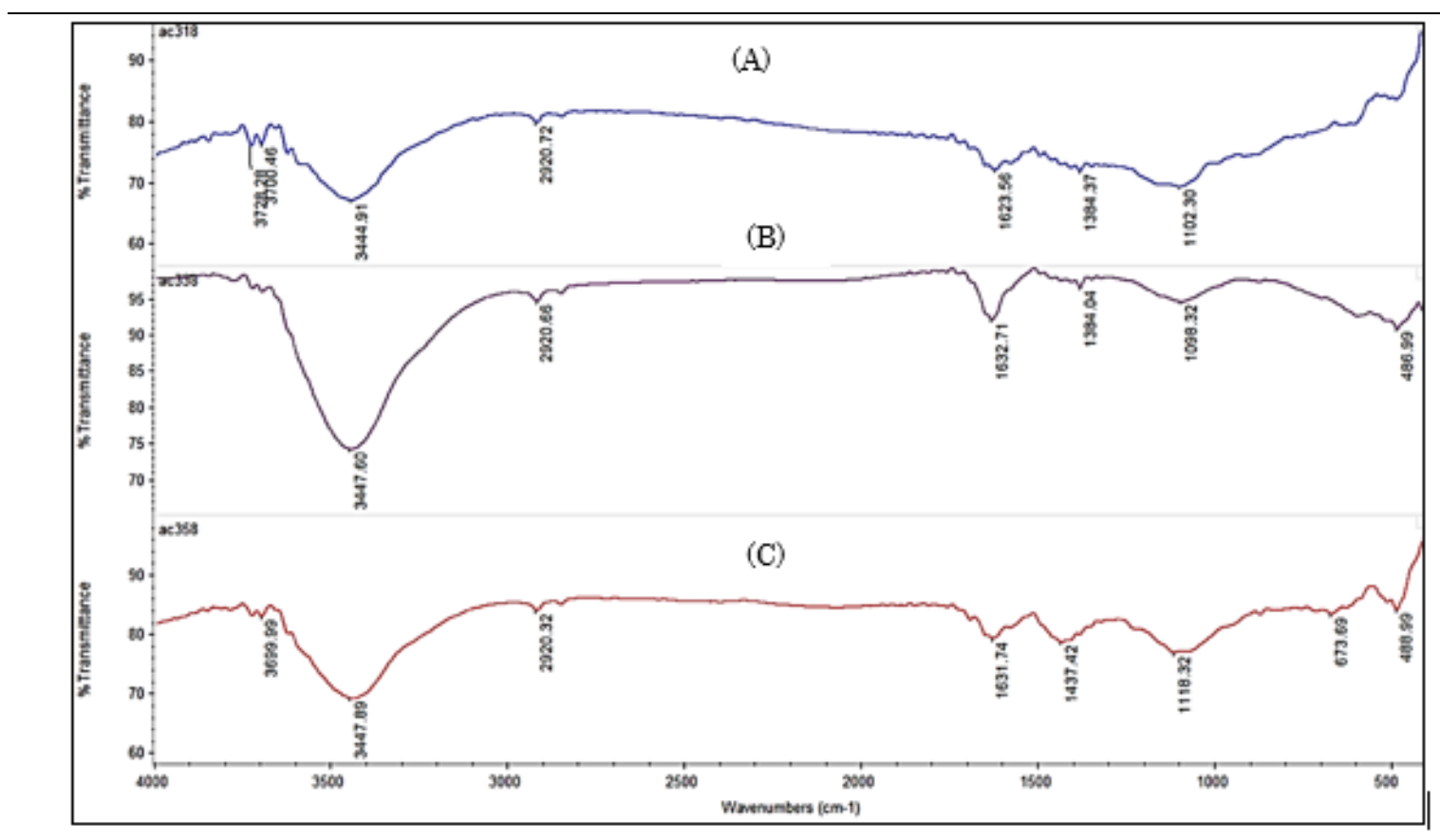

Fig. 1. Functioning Group Analysis of the BAC at Different Microwave Irradiation Power

High ash content in the sample indicates the amount of inorganic material presented from the activation process and the number of treatments that might require (Anisuzzaman et al., 2016). In biomass materials, $\mathrm{C}, \mathrm{H}$ and $\mathrm{O}$ are the main components, and during combustion, $\mathrm{C}$ and $\mathrm{H}$ will be oxidized by exothermic reactions (Jayaraman and Gokalp. 2015). In the current study, raw bamboo initially consists of moderately carbon content (48.64\%) and low nitrogen $(0.14 \%)$, sulfur $(0.11 \%)$ and hydrogen $(6.75 \%)$ content. With the irradiation treatment, $\mathrm{N}$ content was eliminated, and $O$ content was reduced. The study indicated that $100 \mathrm{~W}$ is sufficient to be used in the treatment to eliminate unwanted components in the BAC. By increasing the irradiation power, the temperature and energy supply to the system might also increase, but an insignificant impact on the composition of BAC has been observed.

Functional group analysis of BAC was analyzed using FTIR, and the spectrum was revealed in Figure 1. The functioning group profile for the three-sample showed a similar spectrum profile based on the results. The BAC was produced broad hydrogen-bonded $\mathrm{O}-\mathrm{H}$ stretching bands centred between 3400 and $3450 \mathrm{~cm}^{-1}$. C-O stretch bond also appeared at wavenumber $1300-1000 \mathrm{~cm}^{-1}$ and grouped as an ester. The prepared AC showed the carboxylic acid $(-\mathrm{COOH})$ functional group at a broad peak. The $C=C$ stretching bands for aromatic rings appeared around $1650-1300 \mathrm{~cm}^{-1}$ outside the usual range. The possible group that occurred at 2850-3000 $\mathrm{cm}^{-1}$ were the alkane $\mathrm{C}-\mathrm{H}$ group. While at wavenumbers between 600 - 900 $\mathrm{cm}^{-1}$, weak bands appeared to belong to the $\mathrm{C}-\mathrm{H}$ or $\mathrm{O}-\mathrm{H}$ group.

From the results, a shifting of functional group was occurred between activation processes of MW-ultrasonic due to the adsorption of a chemical activating agent. Horikawa et al. (2010) claimed that increasing activation temperature had decreased the functional group of activated carbon. Besides, many peaks were appeared at $2920 \mathrm{~cm}^{-1}$ and 2850 $\mathrm{cm}^{-1}$ in BAC, indicating that BAC was the most aromatized. Lactones, ketones, carboxylic, 
anhydrides and aromatic rings are the main possible surface functional groups in biomass material available in BAC (Sumanatraku et al., 2015). Some of the functional group that appeared from this result is similar to the functional group as reported by Ahmad and Hameed (2010), Wang et al. (2012) and Rui, Amano and Machida (2013).

Table 3. Surface Area and Total Pore Volume of BAC

\begin{tabular}{|c|c|c|}
\hline $\begin{array}{l}\text { Sample } \\
\text { code }\end{array}$ & $\begin{array}{c}\text { Surface } \\
\text { area }\left(\mathrm{m}^{2} / \mathrm{g}\right)\end{array}$ & $\begin{array}{c}\text { Total pore } \\
\text { volume } \\
\left(\mathrm{cm}^{3} / \mathrm{g}\right)\end{array}$ \\
\hline BAC A & 646.87 & $2.8 \times 10^{-1}$ \\
\hline BAC B & 612.52 & $3.9 \times 10^{-1}$ \\
\hline BAC C & 607.41 & $2.6 \times 10^{-1}$ \\
\hline
\end{tabular}

The BET surface areas corresponding to the chemical activation with different $\mathrm{Mw}$-ultrasonic power is shown in Table 3. The BET surface area of activated carbon is essential because, like other physical-chemical properties, it may vigorously affect the behavior and reactivity of the activated carbon. The current results, as tabulated in Table 3 suggested that the modified BAC possess greater surface area as well as pore volume. In this study, BAC A gave a high surface area value, which is $646.87 \mathrm{~m}^{2} / \mathrm{g}$. The higher surface areas might be due to the opening of the restricted pores during irradiation and ultrasonic exposure, and higher carbonization temperature.

The presence of the pore structure on the surface of the BAC in this study was revealed by scanning electron microscope analysis as depicted in Figure 2. According to the results in Figure 2, a large surface area and porous structure of the activated carbon have been obtained due to the well-developed pores during Mw- ultrasonic activation process.

During the activation process, thermal expansion will generate the breakdown of precursor material and pore will be developed. Exposure to the high temperature and the presence of the activating agent $(\mathrm{KOH})$ will increase the reaction rate, and thus this will lead to the formation of well-developed pores (Sajab et al., 2011). After carbonization, more pore structures are developed, followed by some cavities and crack formation.

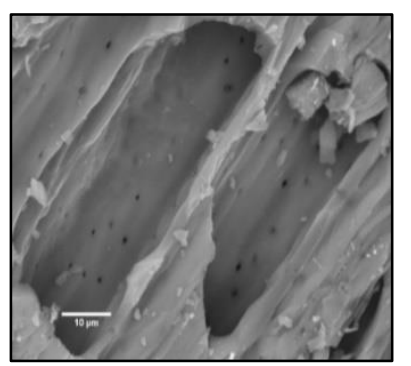

BAC A

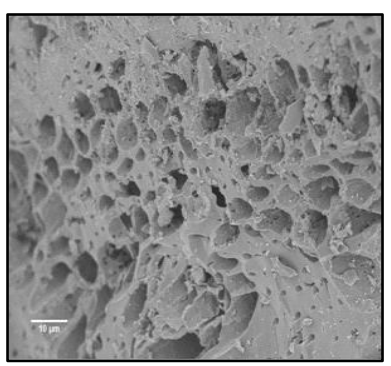

BAC B

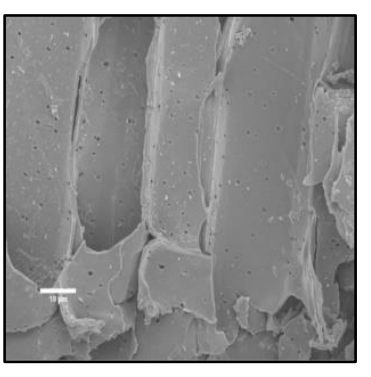

BAC C

Fig. 2. Morphology of $B A C$ after $M w-U$ Activation and Carbonization at $800^{\circ} \mathrm{C}$

Besides, the cavities on the rough surfaces of carbons were aggressively attacked by the chemical agent $(\mathrm{KOH})$ during the activation process. Thus, the interior of the holes created from the reaction expanded uniformly. Besides, cellulose in carbonaceous material is converted to porous solid carbon, which leads to an open pores structure, thus developing the cavities of AC through the process (Jain et al., 2015). The bamboo precursor clearly showed an excellent texture of $A C$ by the presence of the canal structure, which is associated with cellulose fibers. In addition, the external surface of BAC with full of cavities 
and irregularity indicates that the enhancement of temperature influenced the development of porosity material. Moreover, $\mathrm{KOH}$ used in the study can easily be diffused into the carbon microspore and provided a large surface area of BAC.

\section{Electrochemical Properties of BAC}

BAC A with a higher Brunauer-EmmettTeller (BET) surface area of $646.87 \mathrm{~m}^{2} / \mathrm{g}$ and $\mathrm{C} / \mathrm{O}$ ratio was used to determine the specific capacitance $\left(C_{s}\right)$. According to Jiuli et al. (2016), access to the capacitive performance of $A C$ in specific capacitance value has been contributed by the porous texture of carbon with high BET surface area value, moderate pore size and reinforce hydrophilicity. Cyclic voltammetry $(\mathrm{CV})$ was conducted using the electrode made from the AC A. The high porous electrode with the high surface area was an important criterion for a supercapacitor.

However, some researchers had produced moderate BET surface area within the range of $600-900 \mathrm{~m}^{2} / \mathrm{g}$ but gave a higher specific capacitance, $C_{s}$ values between 50-200 $\mathrm{Fg}^{-1}$. Another study by lqbaldin et al. (2013) also claimed that the porous structure developed during the activation process influences supercapacitor performance. The electrode developed from porous structure carbon has provided a high storage capacity and can withstand high current density. Hence, the pore development was crucial for the migration of electrolyte ions and occupied the available pores in carbon material. It repetitively forms a layer at the interface of electrolytes in the supercapacitor.

In this work, the BAC CV curve was conducted at a scan rate from 10 to $150 \mathrm{mVs}^{-1}$ and a potential range of -1.0 to $0.0 \mathrm{~V}$ in 1 $\mathrm{mol} / \mathrm{L} \mathrm{KOH}$ electrolyte. The aqueous electrolyte has been selected in this study because it can provide higher specific capacitance and better capacitance stability with potential or current increase. Zhang, Xiao and Qiang (2014) reported that AC is a highly capacitive material and electrochemical reversible with good stability can be performed well in the alkaline or aqueous $\mathrm{KOH}$ electrolyte. Figure 3 showed the value of $C_{s}$ in different types of scan rates $\left(10,25,50,75,100\right.$ and $\left.150 \mathrm{mVs}^{-1}\right)$.

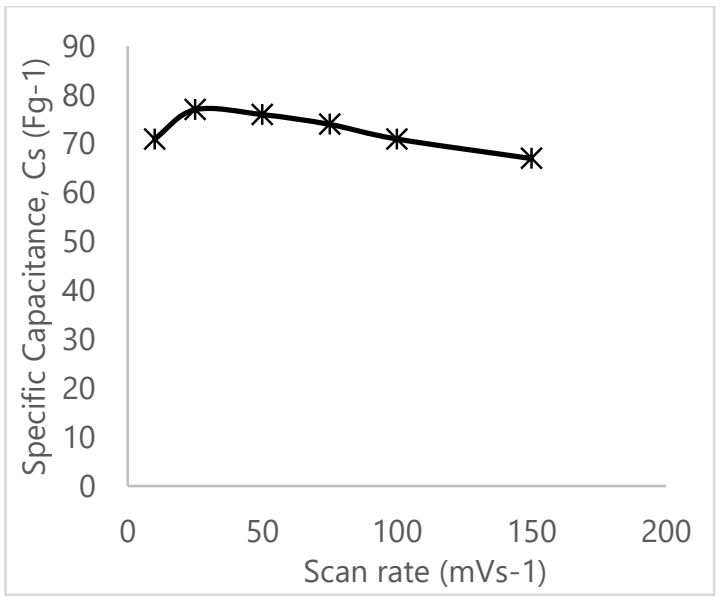

Fig.3. Specific Capacitance of BAC A at Different Scan Rate for CV

The results revealed that the scan rate of $25 \mathrm{mVs}^{-1}$ gave higher values of $C_{s}$ for $C V$, which is $77 \mathrm{Fg}^{-1}$. The capacitance was dropped as the scan rate ascended. The descending value of $C_{s}$ was started at scan rate of $50 \mathrm{mVs}^{-1}\left(76 \mathrm{Fg}^{-1}\right)$ followed by $75 \mathrm{mVs}^{-1}(74$ $\left.\mathrm{Fg}^{-1}\right), 100 \mathrm{mVs}^{-1}\left(71 \mathrm{Fg}^{-1}\right)$ and $150 \mathrm{mVs}^{-1}$ with $67 \mathrm{Fg}^{-1}$. The distorted CV curve might be due to poor rate performance, indicating the narrow mesopores that will limit the fast transfer of electrolyte ions (Ruan, Ai and Lu, 2014). With the increment of scan rate, the penetration of electrolyte ions into mesopores of active carbon can be kinetically limited and impact the charge build-up of the process. 


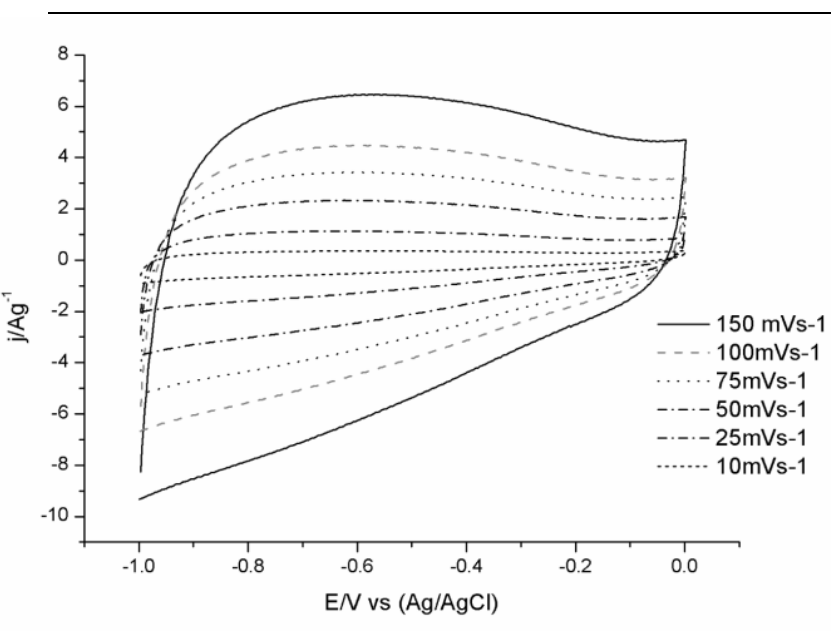

Fig. 4. CV Curve of $B A C A$ in $1 \mathrm{~mol} / \mathrm{L} \mathrm{KOH}$ at Different Scan Rate

The cyclic voltammogram of the BAC A is illustrated in Figure 4. The obtained curve was the quasi-rectangular shape of carbon material and symmetric to the horizontal axis, indicative of capacitive behavior. From the result, a rectangular shape was formed at a higher scan rate, which is ascribed to the resistance of ion migration in micropores. Besides, the increase of the scan rate aggravates the delay of the current to reach a horizontal value after reversal of the potential scan. The dependency pattern of voltammetry currents to scan rate has been used to evaluate the reversibility of electrode material. The reversible curve profile was observed in this study, representing the mechanism of electrostatic charge separation at the electrode-electrolyte interface.

At scan rates of $150 \mathrm{mVs}^{-1}$ and $-0.6 \mathrm{~V}$, the $B A C$ electrode has a higher peak due to the oxidative - reduction of the functional group with oxygen. However, the broadened CV curve was hard to determine any presence of oxygen. The rectangular shape of the CV curve implies a quick ion diffusion and good charge propagation in BAC A at a lower scan rate of $25 \mathrm{mVs}^{-1}$ due to the adequate soakage of electrolyte into the micropores on AC (Barzegar et al., 2015). The present study of cyclic voltammogram curve gave a similar result from other literature, which produced higher specific capacitance with a large area of CV curves (Manyala et al., 2016; Feng et al., 2016).

\section{Charge and Discharge Galvanostatic Anal- ysis}

Charge and discharge curves have been used to determine the specific capacitance $\left(C_{s}\right)$ of the developed BAC A and to identify the stability of the electrode from BAC. The data is tabulated in Table 4 with a current density of 0.3 to $10 \mathrm{Ag}^{-1}$ and at a potential of $-1.0 \mathrm{~V}$ to $0.0 \mathrm{~V}$. From the result in Table 4 , the $C_{s}$ value for BAC A was changed from $33-80$ $\mathrm{Fg}^{-1}$ with the given current density from 0.3 to $10 \mathrm{Ag}^{-1}$. A higher $C_{s}$ value of $80 \mathrm{Fg}^{-1}$ was obtained at the low current density of $0.3 \mathrm{Ag}^{-1}$, whereas at a higher current density of $10 \mathrm{Ag}^{-}$ 1, giving a $C_{s}$ value of $33 \mathrm{Fg}^{-1}$.

Table 4. Specific Capacitance of BAC A at Different Current Density for CDC

\begin{tabular}{cc}
\hline $\begin{array}{c}\text { Current } \\
\text { density }\left(\mathbf{A g}^{-1}\right)\end{array}$ & $\begin{array}{c}\text { Specific capacitance, } \mathbf{C}_{\mathbf{s}} \\
\left(\mathbf{F g}^{-1}\right)\end{array}$ \\
\hline 10 & 33 \\
7.0 & 36 \\
5.0 & 39 \\
3.0 & 43 \\
1.0 & 54 \\
0.5 & 65 \\
0.3 & 80 \\
\hline
\end{tabular}

Then the CDC of BAC A was plotted using linear voltage vs time profile as illustrated in Figure 5. The results reveal that the $C D C$ of the BAC A was the asymmetric triangular shape representing an overwhelming EDL feature where almost no pseudo capacitance has been observed in the discharge branches 
due to the limited contribution to overall capacitance. The curves that exhibit near triangular shapes indicate the electrode's ideal charging and discharging behavior.

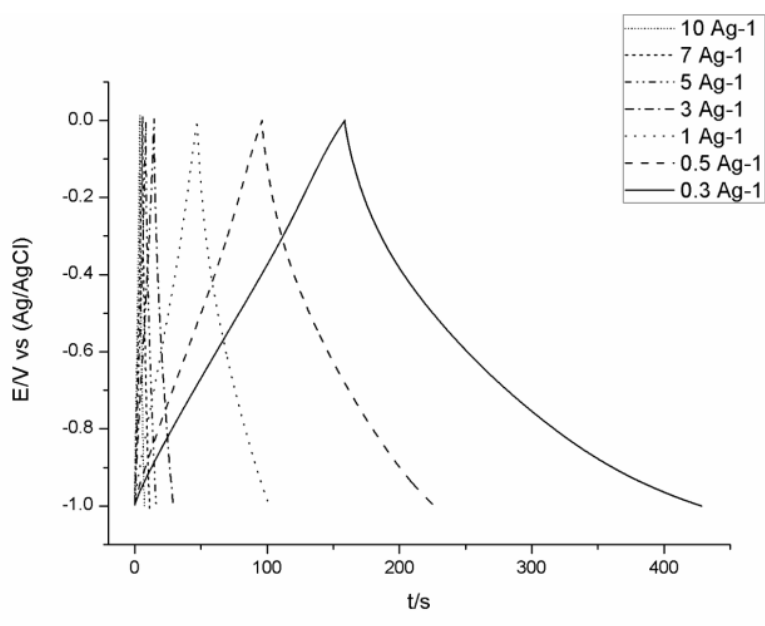

Fig. 5. Galvanostatic CDC Curve of BAC A at Distinct of Current Density

Peng et al. (2013) reported that good electric double layer capacitor behaviors are observed from good linearity and symmetrical triangle. The longer charging and discharging time was expected, as illustrated in Figure 5, due to the functional group of $A C$. The electrode's total resistance or series of resistance (Rs) can be observed from the small internal resistance (IR) drop at the beginning of the discharge process.

A sharp drop in the initial voltage of the discharge curve was found from the CDC output. However, the voltage dropped as observed from the current density below $1 \mathrm{Ag}^{-1}$ at the beginning of the discharge stage originating from IR is negligible. One of the possible factors for this phenomenon was the diffusion mechanism that limits the movement of the electrolyte ions in the electrode pores. In the $\mathrm{KOH}$ aqueous electrolytes solution, the micropores (pore size $<0.5 \mathrm{~nm}$ ) are generally considered too narrow for double layer formation and pores larger than $2 \mathrm{~nm}$ is too wide. The high $C_{s}$ value of $C D$ galvanostatic $\left(80 \mathrm{Fg}^{-1}\right)$ at a lower current density of 0.3 $\mathrm{Ag}^{-1}$ reveals a good energy storage output capacity at a lower current density.

BAC A produces a longer discharging duration and verifies the superior capacitance of the BAC capacitor. Hence, a longer time duration is contributed to large charge storage ability. The $C_{s}$ value for BAC A gives a good rate capability and thus verifies the advantages of BAC in supercapacitors.

The behavior of CV and CDC in charge storage for supercapacitor electrode is associated with the properties of AC such as high edge plane density, higher carbon crystallinity for charge transporting of ions, the functional group of carbon material and combination of micropores and mesopores structure which produce wider charge transport of ions (Mo et al., 2013). The result obtained in $C V$ and CDDC analysis showed that pores of ions transfer is related to AC's functional group and led to the electrostatic impedance spectroscopy (EIS) analyzed.

\section{Electrochemical impedance}

For further understanding of the electrochemical behavior of the BAC electrode, electrical resistances and ion transport behaviors of the electrode were determined using EIS analysis. The EIS was carried out in the range of $10 \mathrm{kHz}-10 \mathrm{MHz}$ and produced Nyquist plots, as illustrated in Figure 6. In the Nyquist plots, charge transfer resistance $\left(R_{c t}\right)$ at the electrode-electrolyte interface was observed through arc formation. As illustrated in Figure 5 , the result appeared with no semicircles, which might be due to the low $R_{c t}$ value in aqueous $\mathrm{KOH}$. Increment of electrode hydrophilicity with a higher surface area of $A C$ was one of the factors contributing to this condition. Theoretically, hydrophilic material will encourage more rapid diffusion of the ions 
and accumulation of the ions on the surface of the porous electrode might occur that lead to the higher specific capacitance of the material. Built-up charges will happen in the process and gave significant supercapacitors behaviors for the produced BAC.

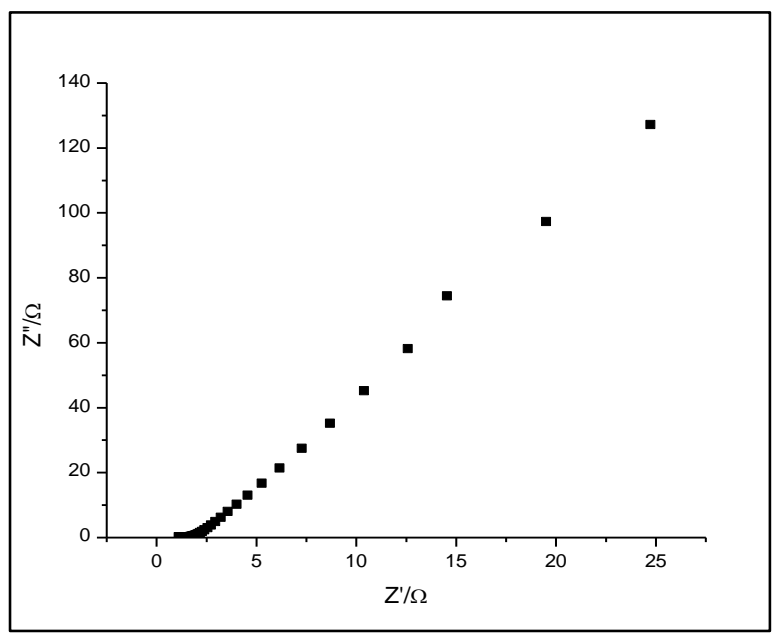

Fig. 6. Nyquist Plots of BAC A Capacitor

An inconspicuous semicircle at the highfrequency region and a straight line at low frequency appeared in the impedance graph. At the high-frequency region, a series of resistance $\left(R_{s}\right)$, namely ionic resistance of the electrolyte, intrinsic active material resistance and contact resistance between electrode and collector, can be determined as an intercept at the real axis (Gogotsi et al., 2014). At low frequency, plot through $45^{\circ} \mathrm{C}$ phase angle represents higher diffusion resistance of the electrolyte ions. According to Siller et al. (2011), movement of the ion worked well on the surface of the electrode, but the inner pores might not be accessible, and it may be plausible to reduce the capacitance. Good electrode conductivity can be observed based on the internal resistance of the $A C$ electrode at a low region below $0.5 \Omega$.

Moreover, semicircle that appeared nearly at $1 \Omega$ was also described on the high conductivity of the electrode [38]. Wang et al.
(2015) has suggested that an excellent charge storage behavior can be observed from a smaller high-frequency intercept with the real axis, smaller arc size and vertical straight line in the low frequency of the Nyquist plots. $R_{s}$ and $R_{c t}$ were dropped at the beginning of the discharge curves, and smaller diffusion resistance through the pores in the active materials was obtained, associated with the excellent intrinsic electronic properties of carbon material. In this study, the higher BET surface area of BAC provided better conductivity owing to the rapid electron and ion diffusion. Low ionic resistance within its porous structure accelerated the fast diffusion of ions and facilitated the fast transfer between electrode-electrolyte surfaces. Similar work also has been reported by Zhang et al. (2016).

\section{CONCLUSIONS}

The Bamboo Activated Carbon (BAC) was prepared under Microwave-ultrasonic activation (Mw-U) using potassium hydroxide $(\mathrm{KOH})$ and carbonized at $800^{\circ} \mathrm{C}$ to increase the surface area and pore development of $A C$. The activation using $\mathrm{Mw}-\mathrm{U}$ could reduce volatile matter in BAC and provided higher carbon content ranging from $63 \%-83 \%$ at $100 \mathrm{~W}-500 \mathrm{~W}$ of microwave irradiation power.

The FTIR spectrum indicates that the main functional group present in the BAC was hydrogen-bonded $(\mathrm{O}-\mathrm{H})$ stretching bands cantered between 3400 and $3300 \mathrm{~cm}^{-1}$ and CO stretch bond grouped as an ester that appeared at wavenumber $1300-1000 \mathrm{~cm}^{-1}$. The $\mathrm{C}=\mathrm{C}$ stretching bands for aromatic rings appeared around $1650-1300 \mathrm{~cm}^{-1}$, and the alkane $\mathrm{C}-\mathrm{H}$ group presented at $2850-3000 \mathrm{~cm}^{-}$ 1. This functional group represented cellulose, hemicellulose, and lignin as the main compo- 

Potassium Hydroxide Assisted By Microwave-Ultrasonic Irradiation

nents in the bamboo structure. The morphology analysis indicated the presence of the pore on the surface and internal structure of the produced BAC. BET analysis indicated that BAC obtained at $100 \mathrm{~W} \mathrm{Mw}-\mathrm{U}$ activation provided the highest surface area of $646.87 \mathrm{~m}^{2} / \mathrm{g}$ with a total pore of $2.8 \times 10^{-1} \mathrm{~cm}^{3} / \mathrm{g}$. The electrochemical analyses were measured and showed that the high specific capacitance, $C_{s}$ of $\mathrm{BAC}$ is $77 \mathrm{Fg}^{-1}$ at $25 \mathrm{mVs}^{-1}$ in $1 \mathrm{~mol} / \mathrm{L} \mathrm{KOH}$ electrolyte for CV. While in galvanostatic CDC at lower current density, $0.3 \mathrm{Ag}^{-1}$ produced higher specific capacitance, $80 \mathrm{Fg}^{-1}$ in aqueous electrolyte. With these electrochemical characteristics, BAC can be used for supercapacitor applications.

\section{ACKNOWLEDGEMENT}

The author is gratefully acknowledged to Universiti Teknologi MARA (UiTM) for financially and technically supporting this research under 600-IRMI/DANA 5/3/BESTARI (129/2018) and highly appreciation to Malaysia Ministry of Higher Education for the continuous support in the academic research

\section{REFERENCES}

1. Ahmad, A. A. and Hameed, B. H. (2010). "Effect of preparation conditions of activated carbon from bamboo waste for real textile wastewater," Journal of Hazardous Materials, 173 (1-3), 487 - 93.

2. Anisuzzaman, S. M., Joseph, C. G., Krishnaiah, D., Bono, A., Sualia, E., Abang, S., Fai, L. M. (2016). "Removal of chlorinated phenol from aqueous media by guava seed (Psidium guajava) tailored activated carbon," Water Resources and Industry, 16, 26-39.

3. Barzegar, F., Momodu, D. Y., Fashedemi, O. O., Bello, A., Dangbegnona, J. K. and
Manyala, N. (2015). "Investigation of different aqueous electrolytes on the electrochemical performance of activated carbon-based supercapacitors," Royal Society Chemistry Advance, 5, 107482 107487.

4. Çeçen, F. (2014). "Activated Carbon". Kirk-Othmer Encyclopedia of Chemical Technology, 1-34.

5. Cukierman, A. L. (2013). "Development and environmental applications of activated carbon cloths" International Scholarly Research Network Chemical Engineering, 31-62.

6. Feng, H., Hu, H., Dong, H., Xiao, Y., Cai, Y. and Zheng, M. (2016). "Hierarchical structured carbon derived from bagasse wastes: A simple and efficient synthesis route and its improved electrochemical properties for high-performance supercapacitors," Journal of Power Sources, 302,164-173.

7. Fu, Y., Ding, X., Zhao, J. and Zheng, Z. (2020). "Study on the effect of oxidationultrasound treatment on the electrochemical properties of activated carbon materials," Ultrasonics Sonochemistry," 104921.

8. Gogotsi, Y., Guldi, D., McCreery, R., Hu, C. C., Merlet, C., Béguin, F., Hardwick, L., Frackowiak, E., Macpherson, J., Forse, A., Chen, G. Z., Holt, K., Dryfe, R., Kurig, H., Sharma, S., Unwin, P. R., Rabbow, T., Yu, W., Qiu, F., Juarez, F., Sole, C., Dyatkin, B., Stevenson, K., Cao, Y., Cousens, N. and Noofeli, A. (2014). "Carbon electrodes for energy storage: general discussion," Faraday Discussions, 172, $239-260$.

9. Hao, X., Wang, J., Ding, B., Wang, Y., Chang, Z., Dou, H. and Zhang, X. (2017). "Bacterial cellulose derived interconnected meso-microporous carbon nanofiber networks as binder free electrodes 
for high performance supercapacitors," Journal of Power Sources, 352, $34-41$.

10. Horikawa, T., Kitakaze, Y., Sekida, T., Hayashi, J. and Katoh, M. (2010). "Characteristics and humidity control capacity of activated carbon from bamboo," Bioresource Technology, 101, 3964 - 3969.

11. Iqbaldin, M. N., Khudzir, M. I., Azlan, M., Zaidi, A., Surani, B. and Zubri, Z., (2013). "Properties of coconut shell activated carbon," Journal of Tropical Forest Science, 25 (4), 497 - 503.

12. Itodo, A. U., Rahman, F. W., Hassan, L. G. and Happiness, U. I. (2012). "Sorption energy for atrazine onto devolatilized Vitellaria paradoxa," Iranian Journal of Chemical and Chemical Engineering, 31, 43-52.

13. Jain, $A ., X u, C .$, Jayaraman, S., Balasubramanian, R., Lee, L. and Srinivasan, M. (2015). "Mesoporous activated carbons with enhanced porosity by optimal hydrothermal pretreatment of biomass for supercapacitor applications," Microporous and Mesoporous Materials, 218, 55-61.

14. Jayaraman, K. and Gokalp, I. (2015). "Pyrolysis, combustion and gasification characteristics of miscanthus and sewage sludge," Energy Conversion and Management, 89, $83-91$.

15. Jiang, Z., Liu, Z., Fei, B., Chai, Y., Yu, Y. and Liu, X. (2012). "The pyrolysis characteristics of moso bamboo," Journal of Analytical and Applied Pyrolysis, 94, 48-52.

16. Jiuli, C., Gao, Z., Liu, X., Wu, D., Xu, F. and Jiang, K. (2016). "Hierarchically porous carbons with graphene incorporation for efficient supercapacitors," Electrochimica Acta, 213, 382 - 392.

17. Kalyani, P. and Anitha, A. (2013). "Biomass carbon and its prospects in electrochemical energy systems," International Journal of Hydrogen Energy, 38 (10),
$4034-4045$.

18. Mahanim, S., Asma, I., Rafidah, J., Puad, E., Shaharuddin, H. (2011). "Production of activated carbon from industrial bamboo waste," Journal of Tropical Forest Science, 23 (4), 417 - 24.

19. Manyala, N., Bello, A., Barzegar, F., Khaleed, A., Momodu, D. Y. and Dangbegnon, J. K. (2016). "Coniferous pine biomass: A novel insight into sustainable carbon materials for supercapacitors electrode," Materials Chemistry and Physics, 182, 139-147.

20. Mo, R. J., Zhao, Y., Wu, M., Xiao, H. M., Kuga, S., Huang, Y., Li, J. P. and Fu, S. Y. (2016). "Activated carbon from nitrogen rich watermelon rind for high performance supercapacitors," Royal Society Chemistry Advance, 6, 59333 - 42.

21. Peng, C., Yan, X., Wang, R., Lang, J., Ou, Y. and Xue, Q. (2013). "Promising activated carbons derived from waste tea leaves and their application in high performance supercapacitors electrodes," Electrochimica Acta, 87, $401-8$.

22. Peng, X. M., Hu, F. P., Zhang, T., Qiu, F. X., Dai, H. L. (2018). "Amine-functionalized magnetic bamboo-based activated carbon adsorptive removal of ciprofloxacin and norfloxacin: A batch and fixed-bed column study," Bioresource Technology, 249, $924-934$.

23. Prasetyo, I., Mukti, N. I. F., Fahrurrozi, M., Ariyanto, T. (2018). "Removing Ethylene by Adsorption using Cobalt OxideLoaded Nanoporous Carbon," AJChe, 18, 9-16.

24. Rodríguez, A. J. M. and Mazzoco, R. R. (2010). "Adsorption studies of methylene blue and phenol onto black stone cherries prepared by chemical activation," Journal of Hazardous Materials, 180, 656 $-61$. 
224 Chemical and Electrochemical Properties of Bamboo Activated Carbon Activate Using Potassium Hydroxide Assisted By Microwave-Ultrasonic Irradiation

25. Ruan, C. P., Ai, K. L. and Lu, L. H. (2014). "Biomass derived carbon materials for high performance supercapacitor electrodes," Royal Society Chemistry Advance, 4, 30887 - 95.

26. Rui, W., Amano, Y. and Machida, M. (2013). "Surface properties and water vapor adsorption desorption characteristics of bamboo based activated carbon," Journal of Analytical and Applied Pyrolysis, 104, $667-74$.

27. Sajab, M. S., Chia, C. H., Zakaria, S., Jani, S. M., Ayob, M. K., Chee, K. L., Khiew, P. S. and Chiu, W. S. (2011). "Citric acid modified kenaf core fibers for removal of methylene blue from aqueous solution," Bioresource Technology, 102, $7237-43$.

28. Salanne, M., Rotenberg, B., Naoi, K. (2016). "Efficient storage mechanisms for building better supercapacitors," Nature Energy, 1, 16070.

29. Sillars, F. B., Fletcher, S. I., Mirzaeiana, M. and Hall, P. J. (2011). "Effect of activated carbon xerogel pore size on the capacitance performance of ionic liquid electrolytes," Energy Environment Science, 4, 695-706.

30. Sumanatrakul, P., Kongsune, P., Chotitham, L. and Sukto, U. (2015). " Utilization of Dendrocalamus asper backer bamboo charcoal and pyroligneous acid," Energy Procedia, 79, 691 - 6.

31. Taer, E., Deraman, M., Talib, A., Awitdrus, A., Hashmi, S. A. and Umar, A. A. (2011). "Preparation of a highly porous binder less activated carbon monolith from rubber wood sawdust by a multistep activation process for application in supercapacitors," International Journal Electrochemical Science, 6, 3301-15.

32. Wang, C. H., Du, H. Y., Hsu, H. C., Chang, S. T., Huang, H. C. and Chen, L. C. (2012). "High stability of oxidation of methanol catalyzed by Pt supported by oxygen incorporated bamboo shaped CNTs grown directly on carbon cloth," International Journal of Hydrogen Energy, 37 (14), $10663-70$.

33. Wang, K., Zhao, N., Lei, S., Yan, R., Tian, X., Wang, J., Song, Y., Xu, D., Guo, Q. and Liu, L. (2015). "Promising biomass based activated carbons derived from willow catkins for high performance supercapacitors," Electrochimica Acta, 166, 1 - 11.

34. Wang, Y., Liu, M., Yang, L., Wu, Z. and Zhao, J. (2012). "Adsorption of Pb (II) in aqueous solutions by bamboo charcoal modified with $\mathrm{KMnO}_{4}$ via microwave irradiation," Colloids and Surfaces A: Physicochemical and Engineering Aspects, 414, 1-8.

35. Yang, C. S., Jang, Y. S., Jeong, H. K. (2014). "Bamboo-based activated carbon for supercapacitor applications," Current Applied Physics, 14, 1616-1620.

36. Zhang, G. X., Chen, Y. M., Chen, Y. G. and Guo, H, (2018). "Activated biomass carbon made from bamboo as electrode material for supercapacitors," Materials Research Bulletin, 102, 391-398.

37. Zhang, M. Y., Xiao, J. and Qiang, Z. (2014). Preparation of $\mathrm{N}$-doped activated carbons for electric double layer capacitors from waste fiber board by $\mathrm{K}_{2} \mathrm{CO}_{3}$ activation," New Carbon Materials, 29 (2), $90-95$.

38. Zhang, Y., Cui, X., Zu, L., Xiaomin, C., Liu, Y., Wang, X. and Lian, H. (2016). "New supercapacitors based on the synergetic redox effect between electrode and electrolyte," Materials, 9, $734-47$. 